\title{
Interface
}

\section{CONTRIBUIÇÕES DA PSICOLOGIA AO ESPORTE DE ALTO RENDIMENTO}

\author{
Lucas Vieira de Lima Silva (1) \\ Wilson Graciano dos Santos Filho (2) \\ Adriele Vieira de Lima Pinto (3)
}

\begin{abstract}
Resumo
Este estudo teve como objetivo tecer considerações sobre a psicologia do esporte, sobretudo destacando seus objetivos e contribuições para o esporte de alto rendimento. A psicologia do esporte para ao esporte de alto rendimento? Acredita-se que a psicologia do esporte se constitui um marco determinante na obtenção dos resultados atléticos positivos, uma vez que se os avanços das ciências dos esportes contribuíram para a elevação do nível de rendimento competitivo das equipes e atletas, tornando-os muito próximos em termos qualitativos. O diferencial vem sendo, indubitavelmente, o fator psicológico destes e, portanto, dar credibilidade a estes conhecimentos torna-se imprescindível a qualquer equipe ou atleta que deseja o alcance de resultados cada vez mais significativos. $\mathrm{O}$ estudo foi sistematizado por meio de uma pesquisa bibliográfica desenvolvida em caráter exploratório de leituras, interpretação e fichamentos de textos pesquisados na internet que tratam especificamente sobre a psicologia do esporte. Esta incursão, aliada as embrionárias experiências dos autores deste ensaio, foi determinante para a concretização dos textos constituintes deste artigo. O estudo, ao ser rediscutido contribuirá, certamente, para a realização de outras pesquisas do gênero.
\end{abstract}

Palavras-Chave: Psicologia do Esporte, Esporte de Alto Rendimento, Contribuições.

\section{Introdução}

Atualmente, mais do que nunca, o esporte se constitui um dos fenômenos mais acessado no mudo inteiro. Este acesso se materializa por meio de práticas de diferentes modalidades esportivas, através de canais de TV abertos ou fechados (por assinatura) que oferecem uma série de programas esportivos de toda natureza, bem como pelo consumo de leituras de jornais e revistas especializadas referentes ao tema esportivo em seu sentido mais diversificado possível. O tempo dedicado a esta atividade humana, no mundo moderno é bastante significativo, destacando-se na mídia escrita, falada, televisiva e informatizada.

Por conta, também, disso, o esporte tem despertado a atenção de pesquisadores e estudiosos dos diferentes campos do conhecimento, sobretudo pela forte presença que este fenômeno vem exercendo na vida cotidiana das pessoas, sejam estas atletas ou apenas (tele)espectadores, leitores de 
matérias esportivas que as têm como fonte de estudos e pesquisas ou ainda como profissão, ou simplesmente como forma de lazer.

Diferentes áreas do conhecimento buscam, dentro de suas intenções e interesses de pesquisas, compreender o fenômeno esportivo, conferindo-lhe a relevância que tem demonstrado através de sua indiscutível visibilidade.

Nesse contexto, destaca-se o esporte de alto rendimento, o qual é vivenciado profissionalmente por uma minoria de atletas de alto nível e, consideravelmente consumido por milhões de pessoas no mundo inteiro, enquanto mercadoria de entretenimento.

O crescimento e desenvolvimento do esporte-espetáculo foram possíveis graças aos inúmeros avanços científicos e tecnológicos, surgidos em fins do século XX e início do século XXI. Isto tem proporcionado a formação e preparação de atletas e equipes cada vez mais competitivos, aumentando o nível das disputas entre estes. Estas últimas características comprovam os benefícios performáticos que o esporte alcançou com o desenvolvimento da ciência e da tecnologia.

Não há dúvida que outras ciências do esporte - por exemplo, o treinamento desportivo, a medicina desportiva, a nutrição, etc. - contribuem de forma significativa para o esporte de rendimento. Mas é justamente por conta destas importantes contribuições que o nível físico, técnico e tático das equipes e atletas se elevou possibilitando à psicologia do esporte se destacar, uma vez que sua presença vem fazendo a diferença nos resultados.

Dito de outra maneira, se os níveis atléticos alcançaram patamares de excelência, subtende-se que os resultados das competições seriam, teoricamente, todos iguais entre concorrentes. Entretanto, o diferencial estaria, fundamentalmente, nos aspectos psicológicos das agremiações e atletas, entendendo que uma melhor preparação psicológica seria o diferencial para o alcance das conquistas.

Diante do contexto até aqui apresentado, este estudo, tece algumas considerações sobre a psicologia do esporte, sobretudo destacando alguns de seus objetivos e algumas de suas significativas contribuições para o esporte de rendimento. Nossa principal reflexão girou sobre os objetivos e contribuições da psicologia para o esporte de alto rendimento. Não se trata aqui necessariamente de apresentar todas as contribuições que esta ciência é capaz de oferecer ao esporte-espetáculo, mas propõem-se discutir a temática, à luz do referencial teórico.

O estudo foi sistematizado por meio de uma pesquisa bibliográfica desenvolvida em caráter exploratório através leituras, interpretação e fichamentos de textos pesquisados na internet que tratam especificamente sobre a psicologia do esporte.

O trabalho está dividido em duas partes. Na primeira, discutem-se aspectos mais gerais da história e de definições e conceituações em torno da psicologia do esporte. E, na segunda, apresentamse objetivos e contribuições da psicologia do esporte ao esporte de alto rendimento.

Espera-se que este estudo possa servir de motivação para a realização de outros estudos que discutem e analisam as implicações da psicologia para o esporte de alto rendimento. 


\section{Aspectos Históricos e Conceituais Da Psicologia Do Esporte}

Os avanços científicos e tecnológicos vêm permitindo mudanças significativas no mundo, dando cada vez mais um novo sentido e significado às práticas e atividades humanas ao longo dos tempos.

Dentre essas atividades, destacam-se, por exemplo, o fenômeno esportivo, o qual foi consideravelmente beneficiado com o surgimento da ciência do esporte, das técnicas de treinamento desportivo, com as descobertas e ampliação dos conhecimentos da medicina esportiva, da nutrição e metabolismo, da sociologia do esporte, da administração desportiva moderna, dentre outras ciências que, de forma direta ou indireta, trouxeram importantes contribuições ao esporte de alto nível. Aliás,

\footnotetext{
A contribuição da ciência do esporte para o esporte moderno é inquestionável. $\mathrm{O}$ envolvimento de profissionais especializados como fisiologistas, nutricionistas, fisioterapeutas, médicos e jornalistas é de grande importância devido à crescente competitividade nos esportes [...] (SAMULSKI, 2006, p. 165).
}

Dentre essas ciências e para efeito deste estudo, destaca-se a psicologia que com seus conhecimentos forneceram substanciais informações capazes de auxiliar na obtenção de resultados favoráveis nas performances de equipes e atletas.

Essa relação entre psicologia e esporte, embora possa parecer recente, é um movimento que vem se construindo há algum tempo atrás como revela Goulart (2010, p. 01) ao afirmar que "esporte e psicologia começaram a ter uma relação mais estreita no final do século XIX, quando alguns estudiosos resolveram pesquisar os efeitos dos aspectos psicofisiológicos sobre as atividades físicas e esportivas".

Reforçando o que foi explicitado anteriormente, Sousa Filho (2000, p. 34) esclarece mais ainda a questão dessa relação psicologia e esporte dizendo:

Existem, nos Estados Unidos, referências a trabalhos de Psicologia do Esporte desde o século passado. Fitz (em Davis, Huss e Becker, 1995) conduziu uma investigação no laboratório de anatomia, fisiologia e treinamento físico da Universidade de Harvard em 1895 com relação ao tempo de reação múltiplo e publicou os resultados no Psychological Review. O projeto de pesquisa conduzido por Norman Triplett em 1898 que investigou os efeitos da presença de outros competidores na performance do atleta colocou em evidência a interface entre esporte e psicologia. No Brasil, constitui-se um marco para a Psicologia do Esporte, a seleção de juízes para a Federação Paulista de Futebol, em 1954.

Ou seja, verifica-se que os primeiros estudos sobre psicologia do esporte nos Estados Unidos estiveram preocupados em verificar como os competidores psicologicamente reagiam nas competições diante da presença dos outros atletas concorrentes diretos nas disputas. 
Ao passo que no Brasil, a psicologia do esporte passa a ganhar corpo a partir de sua aplicabilidade na seleção de árbitros para a Federação Paulista de Futebol, em 1954, como já citado anteriormente.

Muito provavelmente, esses pesquisadores não tivessem a dimensão que a psicologia pudesse alcançar hoje em dia, sobretudo no que diz respeito a sua relação com o esporte, particularmente o de alto rendimento.

Fica evidente que a questão não se resumiria apenas a aspectos de ordem e domínio técnico sobre a realização das tarefas, por exemplo, de praticar com extrema habilidade o esporte, seja na condição de atleta, ou na de administrar as competições, na condição de árbitro. Ou seja, havia algo que poderia interferir diretamente nas performances de ambas as situações aqui apresentadas, que seria o aspecto psicológico, tanto do atleta quanto daquele que iria conduzir a partida. Estas primeiras manifestações demonstravam haver a necessidade de se olhar para as reações psicológicas dos sujeitos submetidos em situações de estresse (ou níveis de estresse) desencadeadas em função das situações vivenciadas durante os treinos e competições, comprovando que a busca por um equilíbrio dos níveis de ansiedade, motivação e concentração determinariam um melhor ou pior rendimento de atletas e outros envolvidos diretamente nas pelejas esportivas.

Se aqueles momentos - tanto nos Estados Unidos quanto no Brasil - foram representativos de uma fase efervescente da relação entre psicologia e esporte, pode-se afirmar que sua estabilidade como disciplina se concretizou a partir dos anos 1960, principalmente com,

"[...] a criação de associações, jornais e a conseqüente intensificação da produção científica. Foram criadas, então, a International Society of Sport Psychology (ISSP) e, pouco tempo depois, a North American Society for the Psychology of Sport (NASPSPA). Ainda assim, a Psicologia do Esporte permaneceu praticamente desconhecida para a maioria dos profissionais da psicologia" (op. cit., p 34).

Dessa década de 1960 para cá é possível afirmar que a psicologia do esporte vem evoluindo em pesquisas científicas que lhe permitiu ganhar cada vez mais papel de destaque nos esportes de alto rendimento. Hoje, no campo do planejamento, ganha terreno progressivamente, uma vez que seus conhecimentos permitiram contribuir, muitas vezes, para a reversão das situações adversas das equipes e atletas em situações de treinos e jogos, conduzindo-os às conquistas por meio de técnicas psicológicas e voltadas à obtenção dos resultados esportivos satisfatórios. Pode-se afirmar que estas técnicas em muito contribuíram para controlar os níveis de ansiedade, de motivação, concentração e estresse otimizando, por sua vez, o desempenho dos desportistas.

Mas, afinal, o que vem a ser psicologia do esporte? Diferentes e várias definições já foram propaladas por muitos estudiosos sobre o tema. Não cabe aqui apresentar todas elas, mas aquelas que 
foram possíveis coletar. Sobre isso, pode-se iniciar dizendo que de acordo com Judadov (1974) apud Goulart (2010, p. 02),

[...] a preparação psicológica é definida como o nível de desenvolvimento do conjunto de qualidades e propriedades psíquicas do esportista das quais depende a realização perfeita e confiável da atividade esportiva nas condições extremas dos treinamentos e das competições.

Fica claro que a psicologia do esporte é entendida aqui como o campo do conhecimento que intervém no sentido de oferecer ao atleta condições dele, em situações extremas de treinamentos, reagir de forma perfeita e confiável diante do desafio pelo qual se lhe apresenta. Dito de outra maneira, é pelo nível de desenvolvimento e do conjunto de qualidades e propriedades psíquicas do esportista que a psicologia do esporte age para poder ampliar o nível de confiança e perfeição do atleta na realização das tarefas que lhes são atribuídas. O mesmo autor acrescenta ainda que,

A preparação psicológica é um processo objetivo que se promove em determinado grau na prática esportiva. Ela não deve ser feita de modo acidental ou fortuito e sim por meio de intervenções sistemáticas, realizadas dentro de uma programação que acompanhe e considere a sucessão de acontecimentos esportivos (op. cit., p. 02).

De fato, a preparação psicológica não deve ocorrer de forma solta, contingente e desprendida de um planejamento prévio e bem organizado respaldado em dados científicos e na realidade em que o psicólogo desportista irá atuar. Ela deve ocorrer de forma providencial e engajada com o (e no) contexto das ocorrências esportivas manifestadas.

Expressando de uma forma mais simples o que se vem explicitando até o momento, pode-se afirmar que a Psicologia do Esporte "[...] é o estudo científico dos fatores psicológicos que estão associados à participação e performance nos esportes, exercícios e outros tipos de atividade física" (SOUSA FILHO, 2000, p 34). Ou seja, tudo aquilo que está diretamente relacionado à participação e desempenho nos esportes e em outras atividades que dizem respeito aos fatores psicológicos é de responsabilidade da psicologia do esporte, uma vez que, no campo da psicologia é o que há de específico para lidar com esse mundo esportivo.

\section{Objetivos e Contribuições da Psicologia para o Esporte de Alto Rendimento}

Esta parte do estudo tem como propósito apresentar objetivos e contribuições da psicologia do esporte para o esporte de alto rendimento. Para tanto, respaldou-se em autores que tratam sobre estas questões mais específicas sobre o tema. 
A esse respeito, de maneira mais geral, pode-se afirmar que a psicologia do esporte tem como objetivo principal a administração dos níveis das emoções (controle) a serem apresentadas pelo atleta e a equipe durante as etapas de preparação e competição propriamente dita.

Acrescente-se ainda que "[...] a psicologia do esporte investiga como disciplina científica as causas e os efeitos dos processos psíquicos que acontecem com o ser humano antes, durante e depois de uma atividade esportiva ou de lazer" (FABIANI, 2010, p.08). Observa-se que a psicologia do esporte deverá estar presente não apenas no momento de realização da atividade esportiva, mas também sobre o que antecede e ocorre após esta mesma atividade, principalmente buscando pesquisar e interpretar os agentes motivadores das manifestações que contribuem para um melhor desempenho da equipe e do atleta, ou daqueles fatores desencadeadores e seus desdobramentos que interferem de maneira indesejada no resultado atlético.

Sousa Filho (2000) compreende que os profissionais da psicologia dos esportes estão interessados no alcance de dois objetivos principais, quais sejam: 1) ajudar atletas a usar os princípios psicológicos para melhorar o desempenho atlético; e 2) compreender como a participação em atividades físicas, esportivas, de exercícios e jogos afeta o desenvolvimento psicológico, a saúde e o bem-estar ao longo da vida.

Sobre essa questão ainda dos objetivos relacionados a essa área do conhecimento Goulart (2010, p. 01) reforça dizendo que a psicologia do esporte tem como finalidade

[...] auxiliar técnicos e atletas a entender e solucionar, da melhor maneira possível, as suas dificuldades psicológicas e sociais, sendo que uma tarefa específica do psicólogo do esporte é ajudar emocionalmente os atletas nas fases de insegurança, a fim de que eles possam encontrar rapidamente a sua segurança e autoconfiança, de tal forma que possam realizar suas possibilidades máximas de rendimento na competição.

Verifica-se que a psicologia do esporte nessa passagem se refere a dois objetivos basilares. O primeiro, de ordem mais geral, seria o de ajudar técnicos e atletas a compreenderem e, ao mesmo tempo, serem capazes de resolver suas barreiras tanto psicológicas quanto sociais. E, o segundo, de ordem mais específica, o qual se refere ao papel do psicólogo do esporte, é o de amparar emocionalmente os seus desportistas, principalmente nas fases críticas de instabilidade, visando o reencontro mais rápido possível da segurança e autoconfiança destes sujeitos para obterem os resultados máximos esperados de seus rendimentos atléticos nas disputas. Um outro objetivo dessa área do conhecimento seria o de,

[...] compreender os fatores psíquicos que interferem nas ações do exercício físico e no esporte. Os fatores físicos e psíquicos não são separados no esporte. É importante prestar atenção na influência dos fatores cognitivos, motivacionais e emocionais que exercem influência direta no rendimento esportivo (SAPIENZA, 2010, p. 01). 
A psicologia do esporte contribui para perceber o atleta na sua totalidade, uma vez que contribui para revelar a relação diretamente existente entre fatores psíquicos e físicos. Ou seja, estes fatores não se separam entre si e, por isso, a tríade aspectos cognitivos, motivacionais e emocionais apresentam influência substancialmente direta no rendimento atlético. Com isto, pode-se assim afirmar, o esporte passa a ser espaço/tempo de manifestação e evidenciação dessa inseparabilidade entre físico e psíquico. De fato, amparando-se no que se vem explicitando até o momento é possível verificar que,

A importância da preparação psicológica está em acelerar processos naturais de desenvolvimento das qualidades psíquicas e propriedades da personalidade mais relevantes ao esportista. Ela contribui para desenvolver a tendência à auto-educação da vontade e do auto-aperfeiçoamento ativo do esportista (JUDADOV, 1974) (GOULART, 2010, p. 03).

Aquilo que possa ser mais significativo para o atleta em sua preparação psicológica sobretudo em relação ao que diz respeito à aceleração dos "processos naturais de desenvolvimento das qualidades psíquicas e propriedades da personalidade" - é o que de fato contribui para que ele (o atleta) potencialize sua auto-educação e o seu auto-aperfeiçoamento. Ou seja, a relevância da preparação psicológica deverá guiar-se no sentido de fornecer elementos em que o atleta sinta-se instigado a querer educar-se e aperfeiçoar-se a si mesmo permanentemente. Nesse sentido,

A preparação psicológica para o esportista, de acordo com Judadov (1974) consiste em: Contribuir para o aperfeiçoamento de processos psíquicos: percepções especializadas, representações, atenção, memória, pensamentos etc. (GOULART, 2010, p. 03).

Esses processos psíquicos são possíveis de serem desenvolvidos e aperfeiçoados mediante uma intervenção consciente e qualificada daquele que irá conduzir o trabalho de preparação psicológica. Desta maneira, a psicologia do esporte, através de seu especialista, estará oferecendo subsídios inegavelmente necessários ao esporte de alto rendimento.

A psicologia contribui ainda "[...] para o desenvolvimento de conhecimentos acerca das competições que se irão realizar; criar uma 'atmosfera psicológica' positiva” (GOULART, 2010, p. 03) é uma das tarefas de destaque para a obtenção dos resultados satisfatórios, tanto individual quanto coletivo dos atletas e equipe no esporte de alto rendimento.

Souza Filho (2000), acredita que, 
De fato, a psicologia tem contribuído em muitos dos campos de interesse do psicólogo do esporte. A psicologia cognitiva, com certeza o paradigma dominante na psicologia atual (Robins, Gosling \& Craik, 1999), contribui na tentativa de elucidar como a cognição e as emoções afetam as performances desportivas. Nesse campo, tanto a pesquisa básica como a aplicada nas áreas da atenção, memória, percepção, tomada de decisão, entre outras, são realizadas com esse objetivo (SOUSA FILHO, 2000, p 34).

São inúmeros os objetivos e contribuições da psicologia do esporte ao esporte de alto rendimento. A intenção aqui foi a de fazer um recorte sobre essa questão, trazendo uma reflexão da importância capital desta área do conhecimento em interface com o esporte de alto desempenho do mundo atual: altamente competitivo e de uma excelência nos níveis de preparação jamais alcançados em outros tempos.

Não se trata de colocar aqui a psicologia do esporte como a responsável por todo sucesso dos desportistas e equipes. Não é pretensão tratá-la como tal. Mas como o esporte de alto rendimento alcançou níveis inimagináveis de preparação física, técnica, tática, entre outras, e se as equipes que estão no mesmo patamar demonstram isto em determinadas competições esportivas, não resta dúvidas de que o fator psicológico poderá ser o grande diferencial ao longo de uma destas competições.

\section{Considerações Finais}

Este ensaio objetivou analisar objetivos e contribuições da psicologia do esporte ao esporte de alto rendimento.

De acordo com o estudo, a psicologia do esporte se constitui um marco determinante na obtenção dos resultados atléticos positivos, uma vez que, se os avanços da ciência dos esportes contribuem para a elevação dos níveis de rendimento competitivo das equipes e atletas, o diferencial vem sendo, indubitavelmente, o fator psicológico destes.

Verificou-se que a psicologia do esporte tem como objetivo principal a administração das emoções dos atletas durante a preparação e competição. Além deste, outros mais específicos puderam ser percebidos, tais como:

- Conhecer, discutir e interpretar os agentes motivadores que contribuem para um melhor desempenho da equipe e do atleta, e que interferem de maneira indesejada no resultado atlético.

- Ajudar atletas a conhecerem a si mesmos, seus limites e possibilidades, de forma a melhorar seu desempenho.

- Ajudar técnicos e atletas a compreenderem o trabalho de um grupo, tornando-os capazes de atuarem mais eficientemente, enquanto equipe. 
- Amparar emocionalmente os desportistas, principalmente nas fases críticas de instabilidade, visando o reencontro mais rápido possível da segurança e autoconfiança dos mesmos.

- Compreender como a participação em atividades físicas, esportivas, de exercícios e jogos contribuem ou não para o desenvolvimento psicológico, a saúde e o bem-estar ao longo da vida.

Assim, a relevância da preparação psicológica parece mais significativa, a medida em que guiar o atleta, no sentido de que o mesmo sinta-se instigado a querer potencializar suas capacidades.

\section{Referências}

CASAL, Hiram M. Valdées. Treinamento desportivo e psicologia do esporte. Disponível em: <http://www.ucb.br/mestradoef/RBCM/8/8\%20-\%204/completo/c_8_4_5.pdf >, acesso em: 14 mar. 2010.

FABIANI, Marli Terezinha. Psicologia do Esporte: a ansiedade e o estresse pré-competitivo. Disponível em <http://www.pucpr.br/eventos/educere/educere2008/anais/pdf/182_454.pdf >, acesso em: 14 mar. 2010.

GOULART, Aramis Soares. VOSER, Rogério da Cunha. A Importância da Psicologia do Esporte para o Rendimento do Atleta de Futsal. Disponível em: <http://www.futsalbrasil.com.br/2008/artigos/artigo-de-futsal-7.pdf 14 mar 2010>, acesso em: 14 mar. 2010.

LAVOURA, Tiago Nicola et. al. Olhar da Psicologia do Esporte Sobre a Autoconfiança e a AutoEficácia em Atletas de Canoagem Slalom: relação com o rendimento esportivo. Disponível em $<$ http://cbca.org.br/biblioteca/arquivos/biblioteca_olhardapisicologiadoesportesobre_2006_tiago.pd f>, acesso: 14 mar. 2010.

SAMULSKI, Dietmar Martin. Suporte psicológico aos atletas brasileiros durante as Olimpíadas de Atenas 2004. XI Congresso Ciências do Desporto e Educação Física dos países de língua portuguesa. Escola de Educação Física, Fisioterapia e Terapia Ocupacional, Universidade Federal de Minas Gerais, Brasil.

SAPIENZA, Valéria. O que faz o psicólogo do esporte? Rev. bras. Educ. Fís. Esp., São Paulo, v.20, p.165-67, $2006 . \quad$ set. 2 Suplemento n.5. http://www.saocaetanonatacao.com.br/portal/index.php?option=com_content\&view=article\&id=18 5:o-que-faz-o-psicologo-do-esporte \&catid=43:psicologia\&Itemid=81

SOUSA FILHO, Paulo Gomes de. O que é a Psicologia dos Esportes (Ponto de Vista). Disponível em <http://www.ucb.br/mestradoef/RBCM/8/8\%20-\%204/completo /c_8_4_4.pdf>, acesso em: 14 mar. 2010. Rev. Bras. Ciên. e Mov. Brasília v.8 n. 4 p. setembro 2000.

Sobre os autores:

(1) Lucas Vieira de Lima Silva é professor do Curso de Licenciatura em Educação Física da Universidade Regional do Cariri - URCA.

E-mail: vieira11silva@hotmail.com 
(2) Wilson Graciano dos Santos Filho é professor de Educação Física da Rede Municipal no Município de Santa Rita - PB.

E-mail: dwgraciano@hotmail.com

(3) Adriele Vieira de Lima Pinto é acadêmica do curso de Psicologia da Universidade Federal da Paraíba - UFPB.

E-mail: adri.vlp8@hotmail.com

\section{Como citar este artigo (Formato ISO):}

SILVA, L.V.L; SANTOS FILHO, W.G.; PINTO, A.V.L. Objetivos e contribuições da psicologia ao esporte de alto rendimento. Id on Line Revista de Psicologia, Julho de 2010, vol.1, no.11, p.15-24. ISSN 1981-1189. 